Asian Journal of Information Technology 18 (5): 144-149, 2019

ISSN: $1682-3915$

(C) Medwell Journals, 2019

\title{
Interactive Language Development in a Practical Way with the Help of Neural Learning
}

\author{
${ }^{1} \mathrm{R}$. Vasanthan, ${ }^{2} \mathrm{~S}$. Sivagnanam and ${ }^{3} \mathrm{R}$. Nandhini \\ ${ }^{1}$ Department of English, Anna University, Chennai, Tamil Nadu, India \\ ${ }^{2}$ HIIQ Softwares, Ambattur OT, MTH Road, 600038 Chennai,Tamil Nadu, India \\ ${ }^{3}$ Department of English, BIT Campus, Anna University of Technology, \\ Tiruchirapalli, Tamil Nadu, India
}

\begin{abstract}
Language skill development academy mostly equips a computer setup where students practice in specific tool or software and improves their communication and language skill within their lab timing. This method can only make theoretical practice like examination. It involves expressions and trains communication difficulties over literature but have restrictive access towards speech and language training. Instead in our proposed method, we could enhance their level of learning by inculcating an electronic device usage along with them in their campus which restricts students to communicate only in English inside the college campus. Each and every words used for communication by the students will be recorded and analyzed day by day for the development in their language skill. Skills of language can be processed by the ability of a person to learn a passage or their capability of understanding a conversation and recollecting the important information within the conversation time. We can also find the ability of a person when they can able to converse fluently and when they stammer. Thus, the final report of a person will provide complete details about his starting phase of language skill towards his development of language skill and helps guide them at which point they have to improve.
\end{abstract}

Key words: Langage skill training, recording and reviewing software, ability to impart information, language fluency, stammering situations, development

\section{INTRODUCTION}

Prevailing language coaching methodology monitors the communication ability of learner along with virtual assistance that facilitates students enhancing their level of development in language usage. Everyday researchers enhance the techniques for learning process that improves their ability for language usage. The basic language learning that keeps tracks of language activities and keeps on assisting the learner about their mistakes and the improvised sentences that can be used alternately.

In most of the language labs they have software tools that analyze the language skill of a person and their ability to converse in english without any difficulties. More than checking for difficulties they checks for common mistakes they make while conversing in English phonetics. The equipment send reports on grammatical errors and their alternate word or grammar usage sentences will be taught to them. But this kind of checking will be done only during their training sessions so there may be a chance of malpractice or students might ignore all the reports provided by the software.

We might not assure students spend that much time in language lab for pursuing reading, writing or communication training oriented activities. They may train with some specified set of paragraphs and can easily type those with the help of fellow students or with the comparison with previous report generated. Thus the efficiency of software that provides report about that particular student (Cohen and Riel, 1989). Without real communication skill in English he can able to get good reports from the software by doing all the malpractices.

Moreover, students can only get particular or specified timing for practicing their language and communication skills. It enables improvisation in student pronunciation by recording and suggesting them appropriate kind of pronunciations. Dates back the innovative technical innovation aims on augment course for learners about substantial methods for learning language along with technology (Flower and Hayes, 1981). Technology infusion facilitates students kind of own learning in their own style which can be tried within the possible venue. To enhance a new way of learning, principally because of the fact that a new entry is attractive and well received among the learners because of the freshness. However, Computer Assisted Language Learning (CALL) still remains as one of the popular methods and as some authors defines the process for which a process could computer uses the learning process 
for which it improves his or her own language. Language learning required computer assisted assistance which helps in speaking and limited to basic communication skills. To promote socialized task for promoting language training ability technology assisted learning brings in monotony and slashes the spirit of real world application. The apparent way of learning composed of activity by activity which keeps students stick to it within the stipulated time (Gerald, 2007). Moreover, these traditional technologies could not be monitored by a teacher for each and every student participating in it.

Dates backs students need specialized and professional equipments for recording and makes language practice. Nowadays students use smart phones and can able to install related apps which can incorporate tools that can be incorporated inside the classroom (Hillocks, 2007). As campus activities students asked to narrate incidents from their past likely memories or they are given specific topics and fairly narrate a short story regarding that topic.

\section{MATERIALS AND METHODS}

Language lab learning monotony: Language lab envision students to develop their own basic communication skills, especially in a foreign or target language with devices for electronic sound-reproduction, enabling students to hear model pronunciations of foreign languages and recording and hearing their own voices as they engage in specific workouts (Johannessen, 2001). Generally laboratories provide a teacher console system that permits a teacher to listen to and correct a student individually. Students are individually given activities like sounds of the basic vowels and consonants, pronunciation of vowels and consonants, listening to tapes of conversation by native speakers, watching classical English movies and are provided direction.

Language laboratories offer formal linguistic environments in language acquisition and language learning. It remains as an artificial or formal environment, with the objective of giving the rules and correcting mistakes. Numerous studies propose that grown-ups can not only increase their second language proficiency in informal environments but may do as well as or better than learners who have spent a comparable amount of time in formal situations.

There are a numerous features which could make Language labs perfect in between the coaching time that achieves high rates of participation and interaction between student teacher coordination. After the existence of such technology, it still remains as an objective oriented approach and a sense of an artificial set up prevailing in the technical existence. There are certain issues to which a language lab cannot address because of the formal atmosphere and other limitations associated with a formal setup. Development of language which generally happens effortlessly in a social arrangement is not characteristically present with the activities of the language lab as they are resource focused. Language lab activities do not combine the learners naturally and make them collaborate in the activity in order to give them the real time exposure and practice. This is possible only if the learners are regularly coming together to do a normal activity or task in which their communicative competence is a requirement. Staying with the system does not allow them to free themselves from the feeling of a formal situation and does not provide them the sense of reality. Thus, it can be enlisted that language laboratories primarily being a formal setup to learn a language have the following confines:

- Primarily focused on listening and reading

- Mostly teacher and student activity

- Environment for conscious learning with rules

- Monitor with conscious rules that curtails the freedom of a learner

- Objective in approach

- More learning and less practice

- No assistance for group activities

Ability for effective learning process: The language lab offers enough information regarding the structure, pattern and nature of a language, the other part in the process of language learning that is practicing the knowledge that they have acquired and becoming competent in the selected language is not dealt with enough. This kind of set up brings the students together with software which gives the opportunity for a teacher to monitor a student while being naturally involved in an activity that is subjective. This set up will be able to address all the short comings of a language lab as it gives the freedom to move around.

All the students must be provided with an electronic device which will have a sensor for recording each and every conversation of students. Thus their conversation will be examined by the software with which it will generate immediate report about the last conversation. After each conversation the voice will be translated to text and their quality of language will be scrutinized in all aspects.

Communication and language quality will be analyzed in all aspects starts from type of acceptable slang of that particular language the person is using. It has to analyze each word for its correctness in pronunciation and its voice clarity will be stressed for making the analysis effective. Standard of improving English learning will be enhanced time by time on the supervision of teachers. This can be achieved through five types of basic checking which involves speaking, writing, listening, learning and reading which can be classified for its quality delivered. 


\section{Good:}

- Sentences with proper structure

- With appropriate vocabulary

- With appropriate information

- With appropriate tense

Fair:

- Sentences without proper structure

- With appropriate vocabulary

- With appropriate information

- With appropriate tense

Bad:

- Sentences without proper structure

- Without appropriate vocabulary

- With appropriate information

- With appropriate tense

Poor:

- Sentences without proper structure

- Without appropriate vocabulary

- With information

- Without appropriate tense

Here the spoken English and written English will be categorized and scrutinized according to that. Whenever students like they also have option to practice passage writing for which they get immediate reports of analysis on their language usage, grammatical errors, spelling mistakes, etc. Listening and reading ability of a passage or capability of delivering a conversation which also analyses about the recollection of information conversed within the stipulated time (Robin, 2007).

Real time usage of language skill enhancement: The language taught by live demonstration and every words spoken will be corrected concurrently with its grammatical and pronunciation errors. Language lab provides enough information regarding the structure, pattern and natural slang of a language. The other part of language learning process trains the knowledge that they have acquired and becoming competent in language that is not dealt enough. This brings the students integrity towards correspondence in communication not only with co-students also with teachers.

Detailed report of each and every student will be reviewed by the teacher and the corrections which software cannot be assessed may also be confronted by the teacher. They indulge formal linguistic environments in acquisition and for language learning capable of working in informal setup. Speaking and listening focused on group of language activities where group of teachers are there to give instructions at the same time to get feedback. Even students can handle channels with directions to execute a task and infer the efficiency with the obtained output.

The language support by the lab staffs cannot be denied where the primary formal set up for learning a language. The learners are provided monitoring each and normal activity in which they approach and learning can be achieved naturally. They can compensate the shortcoming of regular language set-up in following ways, It can bring in the speaking skill development which is not substantially supported regular language lab that is primarily focused on listening and reading.

Unlike the normal set-up in which the communication or monitoring is direct and one to one. This facility will offer an indirect monitoring by evoking a feeling of remoteness and detachment (Beatty, 2003).

Group tasks and activities which have the potential for orchestration of a social set-up can be followed up and assessed through this set-up.

The intensity and quality of students' participation can be assessed and encouraged with real time situations and tasks and without being too much conscious about rules.

Can be more subjective by picking up any subject, context and can move to any situation and play appropriate rules with the ambiance of the target situation. It will be handy to provide the students enough practice and perform in actual situations which are very vital for the development of confidence and command in the target language.

Language skill training does not combine the learners naturally and make them collaborate in the activity in order to give them the real time exposure and practice. This can be possible only if the learners are regularly coming together to do a normal activity or task in which their communicative competence is a requirement. In real time learning system the equipment stays awake always and checks for quality of language they are using within the campus time.

Vocabulary correction and skill rating: While each and every conversation is recorded it will be first converted from voice format to text. This can be done using specialized software that can convert the speech to text format with maximum accuracy. So as the basic level of check it categorizes the voice clarity and type of conversation they are undergoing. After the clarity has been rated the optimal slang they have to use for that particular language is permitted and acceptable will be rated. After that ratings the voice will be converted to text format which embed punctuations in the translated text according to the sequence of conversation delivered. This helps in analyzing the person quality of English according to their speech. 
As the next process the text will be undergone basic level of preposition, spelling and grammatical checks. They are rated according to the predefined database entries by providing random check for common noun, preposition and grammatical errors. They compared with the previous entries and rate it accordingly. If they find any new kind of sentences delivered then they wait for approval by the group of monitoring staffs. In every institution they allot a group of language monitoring staffs will take care of English speaking improvisation for students. Day by day they review all the student conversations and checks through their nouns, vocabulary, etc (Krashen, 1981).

The common used words and slang will be reviewed and rated for its quality and the new words will wait for its approval. Ratings will be classified as Good, Fair, Bad and Poor by which the students every day improvisation in language skill will be assessed. After every checking and rating of that specific conversation the tool concludes by providing the alternate suggestions in both text and voice. First the rating will be assessed and then the place where students need to develop and where they find problem will be clearly explained. Then it provides suggested sentences which will improve their quality of language usage that they might be used instead for such situations. For some type of conversation they might provide more than one suggestion which suits the learners own way of conveying a message or reacting to it.

This enhances every students own style of learning and improvisation which they may not copy from others style. It helps in creating trend and style for every other students without doing major alteration in language structure. As this database have maximum options for different styles of conversation sentences students can use language without any repetitions.

Adopted neural learning by language monitors: Every copy of automated review message sent for students will also be sent to the monitoring teachers review. They will monitor every student and do manual changes or corrections which the software could not find out. For speech recognition software might be mistaken when translated to text and punctuated. These monitors recognize the wrongly punctuated sentences and does the peer review on every student language skill.

Student reviews about their language of conversation and the misinterpret information of unrecognizable language. Students might use some other languages during the time of college thus this will be reported to the relevant teachers. So, the students will be warned for speaking in languages other than English.

If any new words is used during conversation that will be comes under the view of review team and they classify the language of that word and if it belongs to other language then that will be classified as bad and poor according to the length of sentences used in other language. If it belongs to English but uttered without clarity then it is rated as fair and will be updated in language database. If they use any new English word which is appropriate then it will be rated as good and added to database by neural learning technique.

Monitoring teachers will review each process and the updates like new words and difference in sentence structure usage will be enhanced by implying neural learning technique. The vocabulary and proper tense structure will be analyzed and as the last review process the manual check will be done. Using neural learning technique the new language structure, sentence and words will be updated automatically and used for further language analyze.

The ultimate goal of developing language skill is not only about conversation review but it also scrutinizes the written skill enhancement. It allows student to type a situation oriented or topic oriented passage which will be further scrutinized by the software for its appropriate sentence and structure formation. Grammatical errors and further peer manual review will also be done and rated for its quality. For this passage checking also it involves neural learning in which the new written words or sentence structure used by the person will be analyzed by the verification team and if it is appropriate then it will be adopted by neural adoption technique.

Every change made in English language and the evolution of changes in English usage and the modifications made in speech modulation. Spell check and grammar verification of English will be assessed for the ability of the learners. Neural auto correction for language will be made along with automated messages. The phonetics corrections for grammatical errors which also include pronunciation correction and the written messages will be given data training by neural technology.

Disciplines created for students inside the educational campus will be augmented because of this technology usage. There will be no unwanted or illegitimate conversation will be ensued inside the campus. Self improvisation of English learning will be upgraded with personalized vocabulary practice which in other words explained as self made English phonetic trainer.

Communication skill will be trained and improvised by the trained English Software. This kind of training eliminates student lack of English speaking skill and their inferiority complex about exposing in public. It apparently eliminates other mates mocking about their mistakes or inability to convey a message. So, if student wants to try new vocabulary practice then they can make it as personal training and correct with their mistakes according to the ratings and reports generated. With this method they could enable their own style and own slang that sweeps every one out of their feet. 
Human emotional collaboration for language improvisation: Human psychology is usually obscure which express each and every feeling in ambiguous method (Bruning and Horn, 2000). For some emotions they use many vernacular words but for some intimate feelings they just express rather than using words. Emotions and circumstances of a person make them utter language in efficient way either it makes it even worse. This would help calculate when the student communicates fluently or at what conditions they stammer.

Students when coming together for a language activity in a class room or a language lab they are conditioned to be in a situation and to think and act according to the situation. The objective of being formal with a specific reason clips off the wings of creativity and freedom. The strong awareness about the presence of people and the presence of the trainer will also slow them down by making them think of the reality.

On the other hand indulgence in a language training activity with live connectivity among the participants from different situations and the trainer will escalate the intensity of participation and contribution. Participants in a language activity, come together to communicate and participate physically along with verbal communication. When they are put into the activity the focus is also over the physical appearance which develops emotional and social anxieties. This is also capable of disturbing the balance among the participants in the activity.

When they do not physically see one another and when there is a feeling of real life situation unlike the regular language lab like artificial atmosphere, the nature of participation and the contribution to the learning activity could be more. Here the awareness about the presence of others comes only with recognition of their vise and the content of their speeches or messages. By exploring students accomplished situation when they can conveniently converse we could help them with the knowledge about that. Thus the team of monitoring teachers able to analyze the students thoughts and they could help them come out of their hesitation.

\section{RESULTS AND DISCUSSION}

Human communication skill and emotional feeling will be analyzed and trained using software learning implements language structure and vocabulary training. By monitoring the students learning and communication activities their progress will be evaluated and accordingly their skill status is graded. Monitoring the significant communications throughout their class timings and analyzed their ability of handling emotional situations will be either positive or inculcate some improvisation.

In Fig. 1 it depicts the assessment for quality level of a student as an example and his detailed skill for quality of his learning process throughout his assessment period.

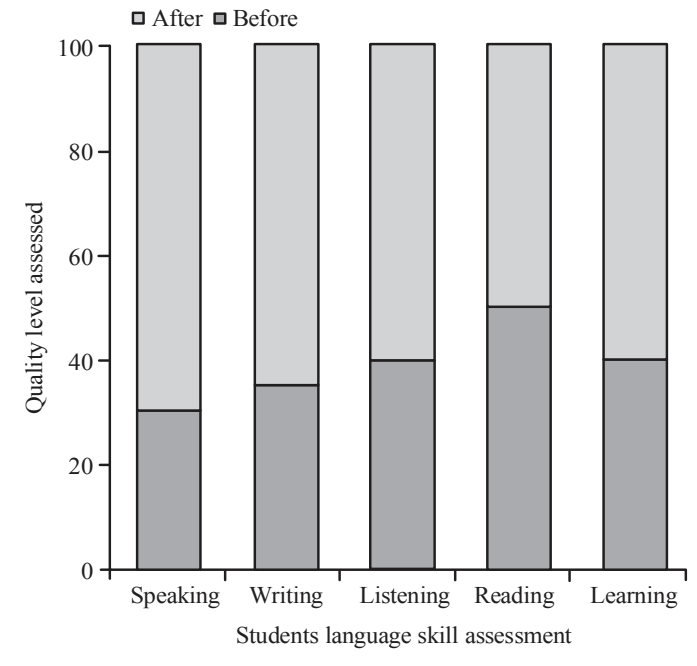

Fig. 1: Skill assessment graph for A student

According to various evaluation examinations like the vocabulary usage of a student, tenses used in their sentence structure, proper information expressed their skill will be calculated and represented as graph. In this their previous level and their skill after undergoing adopted language learning technique is compared and illustrated. With our proposed technique for language development learning each and every student skill development is perceptible and it improvises the student entire language learning ability. It also enhances the possible capability, aptitude and attitude of a student by improvising their proficiency and expertise them in handling language.

\section{CONCLUSION}

In our paper we propose a new technology that attempts to infuse software technology records and scrutinizes the level of English learning capability. It enhances the student level of speaking, writing, listening and conveying information with efficient language structure and vocabulary. This can certainly be beneficial especially with regard to the practice of speaking skills. It provides a natural and informal feeling with the tasks and assignments while being carried out, along with a sense of remoteness that allows the participants to be free and creative. Most significantly it could be a novel way for imparting the rudiments of language and practice on the move or anywhere in the world with all the attributes of the environment for idiosyncratic learning. They also develop and compare the level of a student from his starting phase to next level of language learning. This technology reviews a student ability and rate of adopting a language quickly. This enables not only communication development but also enhances the hidden potentiality. 


\section{REFERENCES}

Beatty, K., 2003. Teaching and Researching Computer Assisted Language Learning. Longman, New York, USA.,.

Bruning, R. and C. Horn, 2000. Developing motivation to write. Educ. Psychologist, 35: 25-37.

Cohen, M. and M. Riel, 1989. The effect of distant audiences on students' writing. Am. Educ. Res. J., 26: 143-159.

Flower, L. and J.R. Hayes, 1981. A cognitive process theory of writing. Coll. Composit. Commun., 32: 365-387.
Gerald, G., 2007. They Say I Say the Moves that Matter in Persuasive Writing. Norton, New York, USA.,.

Hillocks, G., 2007. Narrative Writing: Learning a New Model for Teaching. Heinemann, Portsmouth, England,

Johannessen, L.R., 2001. Teaching thinking and writing for a new century. English J., 90: 38-46.

Krashen, S., 1981. Second Language Acquisition and Second Language Learning. Pergamon Press Inc, Oxford, UK.,.

Robin, R., 2007. Commentary: Learner-based listening and technological authenticity. Lang. Learn. Technol., 11: 109-115. 